\title{
Information Privacy Awareness (IPA): A Review of the Use, Definition and Measurement of IPA
}

\author{
John Correia \\ Washington State University \\ john.correia@wsu.edu
}

\author{
Deborah Compeau \\ Washington State University \\ deborah.compeau@wsu.edu
}

\begin{abstract}
Despite the acknowledged importance of awareness in the information privacy (IP) literature, we lack a consistent and thorough understanding of information privacy awareness (IPA). Drawing on Endsley's model of Situation Awareness, we propose a multidimensional model of IPA and define each of its dimensions. We then conducted a thorough review of the IP literature's use of awareness and synthesize our findings using our proposed model. This paper makes significant contributions by 1) distinguishing between IP knowledge, literacy and awareness 2) consolidating the IP literature's definitions of awareness and providing a new detailed definition 3) proposing a new IPA model that future authors can reference when using or measuring IPA.
\end{abstract}

\section{Introduction}

In today's society of online activity (banking, healthcare, social), we are confronted by a vast array of organizations, both public and private, seeking access to information that people consider private. In a recent study by Pew research, most people felt that being in control of their private information is very important (74\%) or somewhat important (19\%) [50]. More specifically, social security number (95\%), health information $(81 \%)$, location information $(82 \%)$ and content in conversations $(77 \%)$ were considered to be either very or somewhat sensitive information [50].

At the same time, however, information about us is collected, stored, analyzed, transmitted and/or sold/purchased by private, for-profit companies without much regulation. Data brokers "are collecting, analyzing and packaging some of our most sensitive personal information and selling it as a commodity... without our direct knowledge" [49]. This multi-billion dollar industry is greatly unregulated due to the lack of public policy in favor of the consumer.
Privacy protection depends on the actions of individuals, organizations and public policy makers. For example, at the individual level, action depends on people's awareness of the risks of sharing personal information so that they limit their sharing accordingly. Research on the privacy calculus suggests that we actively estimate the value of what we gain by sharing information against the cost or risk of sharing it $[3,5]$. Such a calculation is only valid, however, if our assessment of risk is based on a sound understanding of those risks.

Action at the public policy level also depends in part of the actions and awareness of individuals. A key driver for the creation of public policy is the communication of citizens' concern to policy makers. Again, however, communication of concerns depends on citizens' awareness of the potential risks

Given the importance of individual understanding of privacy risks, this study critically examines the way in which awareness has been used in the privacy literature. We demonstrate that our existing conceptualization is limited, and show how a multidimensional model rooted in Endsley's model of situational awareness provides a richer framework for understanding the different elements that make up IPA. Our multi-level, multi-context awareness construct can be used to select the proper awareness measure depending on how comprehensive the study or in which context the study is focusing on.

To our knowledge, this is the first study that theoretically synthesizes the different ways awareness has been used, measured and defined in IP research. Prior research has claimed to measure awareness in its general form but has fallen short of their claim. Some scholars have measured awareness as just knowledge $[6,41,42]$ while the most cited construct in our field, we would argue measures concern [27].

The remainder of the paper is structured as follows. We begin by explaining our methodology for reviewing the literature. We then provide an overview of the literature and explore the ways in which awareness has been conceptualized as knowledge, literacy and awareness. We introduce Endsley's 
concept of Situational Awareness as a theoretically grounded approach to understanding awareness and develop a multidimensional model of situation awareness applied IP. We present a detailed concept matrix to show which dimensions of our framework have been explored in the literature and to identify gaps and opportunities for future development.

\section{Locating and Selecting Articles}

The methodology for identifying articles in this literature review was tailored around the three step processes recommended by Webster and Watson [43]. Two seminal literature reviews by Smith et al. [35] and Belanger and Crossler [4] were used as the major contributions to conduct backward and forward searches, specifically seeking articles that focused on the key terms: awareness, knowledge, literacy, concern, calculus and paradox.

The backward search of the articles titles, abstract and key terms cited by Smith et al. [35] and Belanger and Crossler [4] resulted in 78 articles. Following the removal of duplicate articles (cited by both reviews) and the analysis of their use of our key terms, 20 articles were selected. The forward search of articles citing these seminal reviews resulted in 40 articles using our key terms. The conclusion of the forward and backward searches resulted in 60 articles to be reviewed in more detail. A backward search on these 60 articles produced another 51 articles which brought our total number of articles to review to 111 .

These 111 articles were reviewed for relevance or measurement of knowledge, literacy and awareness. After a detailed review, 49 were eliminated due to the use of the key term in another context, or it being an unpublished document. For example, two branches of research by $\mathrm{Kehr}$ and $\mathrm{Xu}[20,22,23]$ focused on the psychological aspects of privacy decisions, but did not cover the concepts in our study.

The 62 articles were reviewed in more detail to document their specific use, measurement and definition of the terms aware and awareness. If an article did not use the term aware or awareness, they were removed which brought our final total to 45 articles used in this study.

\section{The Concept of Awareness in Information Privacy Research}

IS privacy research has been focused on privacy concern, privacy calculus and privacy paradox, with privacy concern being the most central. Of the articles reviewed for this study, almost $80 \%$ of them studied concern and almost half of those studied concern as their focal construct. The concept of "awareness" has been implicitly or explicitly acknowledged as important throughout these areas.

Three major measures have been developed for privacy concern: concern for information privacy (CFIP) [36], Internet user's information privacy concerns (IUIPC) [27] and Internet Privacy Concerns (IPC) [19]. CFIP is composed of four first order constructs which were later theorized as second order factors by Stewart and Segar [37]. The first order factors reflect concern about the collection of information, secondary usage, errors and improper access. Although awareness was not directly studied, the essence of individuals concerns about future risks could be tied to their awareness of potential risks. IUIPC used awareness as one of its first order factors, along with collection and control and awareness. This was the first concern model to measure awareness in IP research. IPC was later developed using a combination of CFIP and IUIPC, concluding with six first order factors including awareness.

In addition to these models, a seminal literature review by Smith et al. [35] conceptualized Antecedents - Privacy Concern - Outcomes (APCO). They describe the antecedents of concern to be privacy experience, personality differences, demographic differences, climate/culture and privacy awareness. Although they do not provide an instrument to measure awareness, this further confirms the importance of awareness in studying privacy concern.

The construct of awareness is also important in research on privacy calculus and the privacy paradox. The concept of IP calculus is founded on the notion that individuals conduct a risk-benefit analysis to determine if they are willing to share their information to gain products or services from organizations. Recent studies on the privacy calculus have used a number of different artifacts to study this trade-off including Facebook $[13,40]$, location-based driving products [8,21], location-based social network services [38], products developed specifically for the study [24,26] and general internet usage [10]. The privacy calculus presupposes that individuals can properly assess the benefits and risks of sharing information, which ought to depend on their awareness of the risks. However, of the studies we reviewed on the privacy calculus, only one hypothesized the importance of awareness, and they did not provide the survey questions to analyze how awareness was measured [40].

Privacy Paradox is described as the contradictory actions of individuals who state a certain level of privacy concern but act differently when using technology. Privacy Paradox is a concept that has drawn interest in many different disciplines ranging from economics [1], marketing [12], law [30] and MIS 
$[3,45]$. Several studies in these areas have pointed to the importance of an individual's awareness or knowledge $[1,3,12,45]$ as a partial explanation for the phenomenon.

Throughout the literature, multiple similar concepts are referenced, including awareness, knowledge and literacy. We now discuss each of these three concepts.

\subsection{Knowledge - Literacy - Awareness}

With the noted importance of an individual's awareness of IP, a number of studies have focused on an individual's levels of knowledge [5,41,42], literacy [31,32,39] and awareness [9,29,33] of IP. While the main purpose of this review is to examine how awareness has been used in IP research, we must also acknowledge the literature on knowledge and literacy.

The terms knowledge, literacy, aware, and awareness have all been used to describe an individual's understanding of IP. Often times, these terms are used interchangeably without a true understanding of their differences. If such a distinction were to exist, scholars looking to develop or use knowledge, literacy or awareness scales could be specific on which scales or theories best fit their study. We propose the following distinctions to assist the discipline in finding a consensus around them.

Aware and knowledge are similar because you can be aware of something in a similar way that you can have knowledge of something. Literacy of a subject, on the other hand, encapsulates a broader collection of knowledge. Digital or internet literacy studies were not included in this analysis as they measure a broader concept of literacy $[10,18]$. In IP, we can say that we are aware or have knowledge about companies collecting our private information but it would be limiting to say we are literate about companies collecting our private information. Trepte et al., [39] and Park and Jang [32] proposed that literacy is a multidimensional construct. For example, Park and Jang propose that in order to measure an individual's literacy, a multi-dimensional literacy scale is needed that evaluates an individual's knowledge of technical familiarity, awareness of institutional practices and policy understanding. Trepte et al. added to this construct by proposing two procedural knowledge dimensions and a risk dimension. Following a content analysis, Trepte et al. dropped the risk dimension and consolidated the procedural dimensions into the knowledge about user strategies for individual online privacy control dimension to create the Online Privacy Literacy Scale (OPLIS).

Although Trepte et al. touch on the importance of the time component with their risk dimension, we posit IP awareness takes the proposed literacy scales and adds a situational component which applies the literacy to the current situation and projects future outcomes or develops future risks. To better explain this, we will review the IP literature for definitions of awareness.

\subsection{Information Privacy Definitions of Awareness}

As seen in table 1, the construct of awareness has been defined differently in IP research. Some define awareness as the amount of knowledge $[6,7,17,26,47]$, others define it as understanding [25,27] and $\mathrm{Xu}$ et al. [46] as the abstract application of one's knowledge and understanding. Some authors define awareness across multiple contexts [17] while specifically including [47] and excluding [6] the technology used. Although we include Dinev and Hart's development of social awareness [11], we recognize that it measures the amount of behavior rather than the amount of cognition an individual has towards IP. In addition, even though their definitions of awareness are focused on just the policies and regulations of IP, we also included the awareness definitions from Burkell et al. and $\mathrm{Li}$ et al.

While the literature has explored a number of important themes, there is insufficient definitional clarity around the meaning of awareness. In order to develop a comprehensive definition of privacy awareness, we now turn to literature in psychology which provides a basis to better define IPA.

\subsection{Endsley's Situation Awareness}

First, we must define the term aware. According to the Encyclopedia, aware is defined as "being wellinformed about a particular situation or development" [48]. In IP research, this can be a daunting task since the being well-informed about a particular situation may include the need for an understanding of the technology, policies, regulations and/or common practices used by companies to obtain their private data. Beyond this understanding, individuals must recognize its existence and be able to think abstractly about the consequences of action in a particular situation. To encapsulate the entire definition, we suggest adapting the construct of Situation Awareness (SA) developed by Mica Endsley [14].

SA has been used as a tool to design training and artifacts to increase pilots' awareness so they can be well-informed during varying situations. Since its introduction in the 1980's, SA has been applied to a multitude of different contexts with great success and popularity [44]. We propose that SA can be used to synthesize the literature on IPA, and provide a framework for future research to reference. 
Endsley defines SA as "the perception of elements in the environment within a volume of time and space, the comprehension of their meaning and the projection of their status in the near future" [14 p.36]. SA can be divided into 3 levels, perception, comprehension and projection. Perception deals with the knowledge of the elements in the current situation. Comprehension is described as encompassing "how people combine, interpret, store and retain information" [15 p.3]. Lastly, projection is the ability of an individual to use their level 1 and 2 SA to forecast future events. SA provides a well-established measure to adapt that encapsulates not only the knowledge and comprehension of IP but the ability to abstractly relate the relevant information into the future.

We are not the first to conceptualize the use of SA in the IP literature. Sim et al. [34] introduced an Information Privacy Situation Awareness (IPSA) which subjectively measured individuals level of awareness. We believe our study extends Sim et al. theoretical contribution by further adapting Endsley's model and synthesizing the literature with our proposed model.

Endsley's model cannot be adopted to IP natively. Some adaptation is needed to develop a model specifically for IP. First, SA was developed to measure operator's awareness in situations like flying an airplane or executing a military mission. These types of situations dynamically change in short periods of time with new elements constantly needing to be analyzed. This results in the change in an individuals the level awareness in relatively short time frames. Usually our IP situation does not change dynamically which results in more of constant level of awareness. It could also be argued that we are more concerned with an individual's level of awareness as they begin to use a system rather than while they use it.

Another difficulty to using SA natively is that there are not many elements in IP to perceive. Unlike gauges on an airplane or uniforms on the enemy, the IP context lacks the elements that individuals can use to increase their privacy awareness (companies' privacy policies are a potential exception, though its ability to notify the public has been debated) [28]. Since there is a lack of elements in IP, users must depend on their literacy (collection of knowledge dimensions) as a gauge to perceive the risk elements in IP. We acknowledge the above explained challenges and theorize how we can utilize this seminal theory of awareness to better conceptualize IPA.

\section{Information Privacy Awareness (IPA)}

Drawing on Ensley's levels of SA and combining these with the different knowledge and literacy dimensions results in a new definition of IPA. We define IPA as the literacy of the elements related to information privacy (type 1), the understanding that the elements exist in the current environment (type 2) and projection of their impacts in the future (type 3). Elements in this case are the technology, regulations or common practices used by companies or individuals to collect, use and share user's private information. The environment encompasses the data flow from an individual's computer through to all destinations, and could be in general terms or specific to the artifact in the study (i.e. Facebook). We use the term types instead of levels to acknowledge that there is less hierarchical dependence between them than between Endsley's levels. Type 1 awareness is related to previous studies on knowledge and literacy while type 2 awareness applies level 1 to the current environment. Type 3 awareness relates future implications or risks of the private information collected or the advancements in technology, laws, and common practices.

As seen in the literature, the three major dimensions that individuals need to be aware of are: the technology, the government regulations and the common practices. To accurately conceptualize IPA, we must define each of the three dimensions of IPA.

We define technology information privacy awareness (TIPA) as the knowledge of the technical elements related to IP (type 1), the understanding that the elements exist in the environment (type 2) and projection of their impacts in the future (type 3 ). The technical elements in this case are the hardware and software used by companies or individuals to collect, use and share users private information. The environment is the technologies used to transmit, collect, analyze and store the private data and information. The projection of their impacts relates to the ability of an individual to understand how the current and future advancements in technology can store private information for a long period of time which increases the ability to collect, store, analyze and share private information.

We define regulatory information privacy awareness (RIPA) as the knowledge of the regulatory elements related to IP (type 1), the understanding that the elements exist in the environment (type 2) and projection of their impacts in the future (type 3). Elements in this case are the laws that regulate the interaction between individuals and parties obtaining their private information and the interaction between second and third parties regarding individual's private information. Type 3 awareness in this construct is related to user's projection that laws can change over time which will impact the information that they have already shared. 
We define the common practices in information privacy awareness (CPIPA) as the knowledge of the common practice elements related to IP (type 1), the identification and understanding that the elements exist in the environment (type 2) and comprehension of their impacts in the future (type 3 ). The common practices refer to the policies and strategies used by entities to collect, combine, analyze and trade an individual's private information for their own gain. The environment refers to the data flow from an individual's computer through to all destinations. Type 1 encompasses the tools and practices used by parties while type 2 refers to the present existence of these common practices within the application or artifact(s) being used. Type 3 relates to the risks involved with sharing private information with entities because even though they may seem like a reputable entity at the moment, their intentions or level of security could change over time.

The combination of TIPA, RIPA and CPIPA collectively form a three-dimensional framework representing 9 distinct elements called IPA (figure 1). We will use IPA to synthesize the IP literature for its use and measurement of awareness.

\section{Multidimensional Model of Information Privacy Awareness (IPA) \\ Type 1 \\ Knowledge/Literacy \\ TIPA \\ RIPA \\ CPIPA \\ IPA \\ Type 2 \\ Understanding
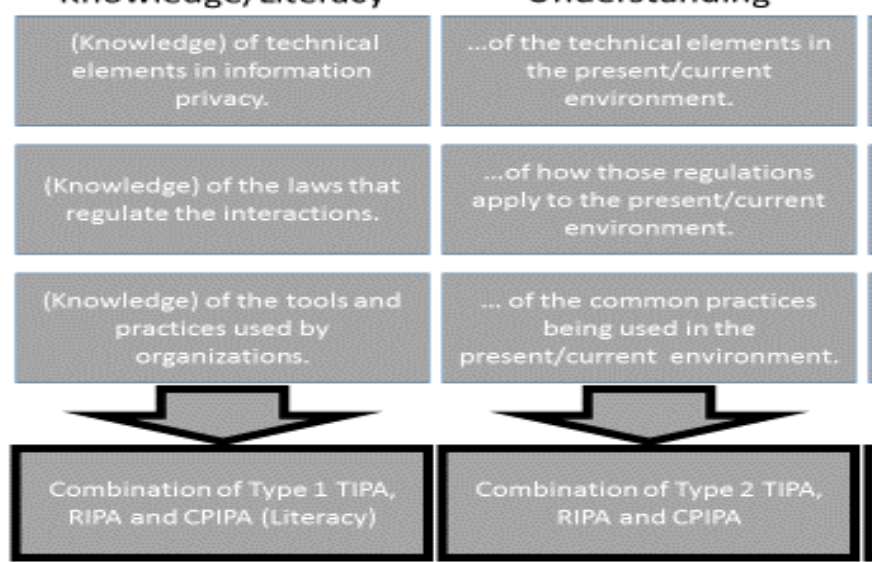 \\ Type 3 \\ Projection
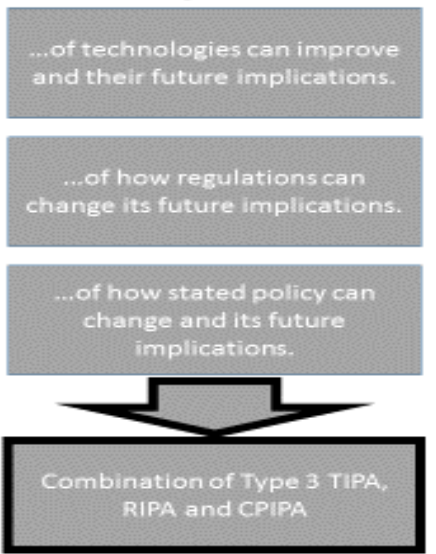

Figure 1. IPA model

\subsection{Knowledge - Literacy - Awareness}

Our proposed awareness construct differentiates from the knowledge and literacy constructs mentioned previously by using them as components of an individual's IPA. Just as the individual knowledge, technical, legal and common practices dimensions combined formed Parks and Jang's construct of literacy [32], their literacy construct is combined with our understanding and projection dimensions to form our IPA construct. The three additional dimensions of Trepte et al. were incorporated into the model as well by including the risk dimension into our projection dimension and the procedural knowledge component in the literacy dimensions of TIPA and CPIPA. To conclude, the collection of knowledge dimensions form an individual's literacy and that literacy is used in conjunction with situational components (understanding and projection) to form IPA.

\section{Analysis Using the Model}

Using the IPA model, the 45 selected articles were reviewed to synthesize their usage of the terms aware and awareness and measurement of awareness.

\subsection{Use of Aware/awareness}

The selected articles were analyzed for the use of the terms aware and awareness. Each instance was further analyzed for its usage in relation to the 9 dimensions proposed in the IPA model and the results were coded (table 2). For example, Acquisi, 2004 [1 p.23] states "is she aware of privacy invasions and the associated risks?". This comment was coded as type 1 and 3 CPIPA and documented that this article used awareness in this context. All articles were reviewed and their results were recorded on a concept matrix shown in table 2.

Our results show that none of the articles used the terms aware/awareness in its full context. $80 \%$ of the coded dimensions were concentrated on the CPIPA and 
only 11 of them fully conceptualize all three types of CPIPA. $87 \%$ of the 45 articles used aware/awareness as a type 1 CPIPA.

Fourteen percent of the coded dimensions used aware/awareness in the TIPA context with only one [41] conceptualizing all three types of TIPA. It is not surprising to see that most of the articles that used TIPA were the articles that focused on knowledge, literacy or awareness [2,6,7,31,39,41]. As with CPIPA, $57 \%$ of the use of TIPA was in relation to type 1 awareness with only two articles mentioned its projection of future implications.

RIPA was the least mentioned type (only six studies). Of these six studies, none of them mentioned how they exist in the current environment or their future implications (Type 2 and 3 ).

\subsection{Measurement of Awareness}

While the preceding analysis focused on how the authors used aware and awareness, we also wanted to look at how awareness was measured. To do this, we further examined 25 articles which formally measured awareness. We initially found 30 measuring awareness or literacy, but 5 of them did not provide a scale to analyze. Literacy measures were included because some of the dimensions overlap with our study. Each scale was analyzed and coded into which IPA dimension was being addressed and whether the question was measuring subjective awareness or not (table 2). Even though there has been a call for more objective measures [2,39] only $48 \%$ of these articles objectively measure awareness..

As with use, $(64 \%)$ of the coded dimensions were CPIPA related with most $(42 \%)$ of the coded measures of CPIPA being in relation to type 2 awareness. The other portion of coded measures resulted in TIPA having $14 \%$ and RIPA having the remaining $21 \%$ of measurement attention. Both TIPA and RIPA questions mainly focused on type 1 awareness (63\% and $50 \%$ ). Also, although a few studies measured all types of awareness in a particular dimension, none of them fully measured IPA. It is interesting to note that even though only one study used awareness in all dimensions of awareness [7], several measures focused on at least one level of each dimension.

\section{Discussion}

This paper makes three principal contributions. First it distinguishes between IP knowledge, literacy and awareness. Future authors can draw upon the distinctions made in this article. These distinctions are not limited to IP; other areas of the IS discipline can use the conceptualizations presented to build their own constructs of knowledge, literacy and awareness specific to their domains.

Second, we consolidate the IP literature's definitions of awareness and propose a new definition of awareness using Endsley's SA definition as a foundation. The proposed definition, which is strongly grounded is a well-established definition of SA, adds credibility and strength to the proposed definition of IPA.

Finally, we propose a multidimensional model of IPA that future authors can reference when using the term IPA or just a dimension or type of IPA. The model was then synthesized with the many different uses and measurement to validate its versatility and completeness. Sometimes authors are focused on a single dimension of IPA, and just need to find a measure of that dimension or use the 3 types of an individual dimension to conceptualize awareness. For example, a study focusing on the legal regulations around IP can conceptualize an individual's awareness by discussing all three types of RIPA and possibly search the literature or develop their own measure of RIPA with questions focusing on each type of the dimension excluding TIPA and CPIPA.

\subsection{Research Implications}

With a more concise and clearly defined concept of IPA and its dimensions, we hope future authors will use the term with improved consistency. The more precise we are with our use of IPA and its dimensions, the easier it will be to build on existing studies. In order to better use the term IPA, we have shown that more conversation needs to be had around the understanding that IPA exists in different environments (type 2) and that there are future implications to sharing our private information (type 3 ). Thus, we also hope future authors will use IPA to develop better measurements of IPA and its dimensions so future studies that state the importance of an individual's awareness can incorporate IPA into their studies.

The literature would benefit from more research on the dimension of TIPA. Many scholars have called for more concentration on the artifact in IS research and in IP research, TIPA is the artifact. We need to better understand which technologies people need to be aware of, which applications use these technologies, and what are the future risks or implications of the advancements in technology. Technology should be the focus of our attention and our study can be used as an example that more attention needs to be given to the TIPA dimension in IP research.

In addition to TIPA, RIPA has shown that more attention needs to be given to the RIPA dimension in both use and measurement. We should look into which 
regulations relate more to our IP, in which jurisdictions do they apply/change, and how we can influence the improvements of regulations to better protect our private information. Future studies could also look into how the different dimensions of RIPA change in different countries and the impacts of these differences to societies.

Lastly, we believe our IPA construct could be adapted in other areas of IS. For example, the area of security has heavily studied awareness and our conceptualization could be applied to more consistently use, measure and define security awareness.

\subsection{Practical Implications}

Our research also has implications for practice, particularly around the importance and design of education and training for privacy awareness. As we better understand how aware we are as a society, we can work to increase our awareness to develop better agency to impact the regulations around the collection and use of our private information online. When developing Privacy Education Training Awareness programs, practice can concentrate on increasing individuals overall awareness by training and educating at each dimension of awareness.

\subsection{Limitations}

We acknowledge that there are limitations of our study. Our review of articles is not exhaustive of the entire literature on IPA. We did not include dissertations and have not conducted a complete search of top journals to look for any missed articles. Nonetheless, because of the breadth of articles included and our systematic use of forward and backward searches in key literature reviews, we are confident that the selected articles are representative of the use and measurement of IPA. Lastly, although we conceptualize the procedural knowledge that Trepte et al. 2015 proposes in our general type 1 awareness constructs, we still need to evaluate if a separate dimension of procedural literacy should be added to our current multidimensional IPA model.

\section{Conclusion}

Protecting individuals' privacy in the information age remains a critical concern. By focusing on the conceptualization of IPA, we contribute to better understanding how individuals' awareness of the threats to their privacy may affect their privacy-related behaviors.

\section{References}

[1] Acquisti, A. Privacy in Electronic Commerce and the Economics of Immediate Gratification. Proceeding EC'04 Proceedings of the 5th ACM conference on Electronic commerce, (2004), 21-29.

[2] Acquisti, A. and Gross, R. Imagined Communities: Awareness, Information Sharing, and Privacy on the Facebook. Proceedings of 6th Workshop on Privacy Enhancing Technologies 4258 LNCS, (2006), 36-58.

[3] Acquisti, A. and Grossklags, J. Privacy and Rationality in Individual Decision Making. IEEE Security and Privacy Magazine 3, 1 (2005), 26-33.

[4] Bélanger, F. and Crossler, R.E. Privacy in the Digital Age: A Review of Information Privacy Research in Information Systems. MIS Quarterly 35, 4 (2011), 1017-1041.

[5] Borena, B., Belanger, F., Ejigu, D., and Anteneh, S. Conceptualizing Information Privacy Concern in Low-Income Countries: an Ethiopian Language Instrument for Social Networks Sites. Proceedings of the Americas Conference on Information Systems, (2015), 1-11.

[6] Brecht, F., Fabian, B., Kunz, S., and Müller, S. Communication Anonymizers: Personality, Internet Privacy Literacy and Their Influence on Technology Acceptance. Proceedings in the European Conference on Information Systems 214, (2012), 1-13.

[7] Burkell, J.A., Fortier, A., Valentino, L., and Roberts, S. Enhancing Key Digital Literacy Skills : Information Privacy, Information Security, and Copyright / Intellectual Property. Canada: Social Sciences and Humanities Research Council, (2015).

[8] Cichy, P., Salge, T.O., and Kohli, R. Extending the Privacy Calculus: The Role of Psychological Ownership. Proceedings in the International Conference on Information Systems, (2014), 1-19.

[9] Culnan, M.J. Consumer Awareness of Name Removal Procedures: Implications for Direct Marketing. Journal of Direct Marketing 9, 2 (1995), $10-19$.

[10] Dinev, T. and Hart, P. An Extended Privacy Calculus Model for E-Commerce Transactions. Information Systems Research 17, 1 (2006), 61-80.

[11] Dinev, T. and Hart, P. Internet Privacy Concerns and Social Awareness as Determinants of Intention to Transact. International Journal of Electronic Commerce 10, 2 (2006), 7-29.

[12] Dommeyer, C.J. and Gross, B.L. What Consumers Know and What They Do: An Investigation of Consumer Knowledge, Awareness, and Use of Privacy Protection Strategies. Journal of Interactive Marketing 17, 2 (2003), 34-51.

[13] Eling, N., Widjaja, T., Krasnova, H., and 
Buxmann, P. Will You Accept an App? Emperical Investigation of the Desicional Calculus Behind the Adoption of Applications on Facebook. Proceedings of the International Conference on Information Systems, (2013), 1-20.

[14] Endsley, M.R. Measurement of Situation Awareness in Dynamic Systems. 1995, 65-84.

[15] Endsley, M.R. Toward a Theory of Situation Awareness in Dynamic Systems. Human Factors: The Journal of the Human Factors and Ergonomics Society 37, 1995, 32-64.

[16] Endsley, M.R. Theoretical Underpinnings of Situation Awareness: A Critical Review Process. In M.R. Endsley and D.J.Garland (Eds), Situation Awareness: Analysis and Measurement, Mahwah, Lawrence Erlbaum, (2000), 1-24.

[17] Ermakova, T., Fabian, B., and Zarnekow, R. Acceptance of Health Clouds-a Privacy Calculus Perspective. European Conference on Information Systems, (2014), 1-13.

[18] Hargittai, E. Survey Measures of WebOriented Digital Literacy. Social Science Computer Review 23, 3 (2005), 371-379.

[19] Hong, W. and Thong, J.Y.L. Internet Privacy Concerns: An Integrated Conceptualization and Four Empirical Studies. MIS Quarterly 37, 1 (2013), 275298.

[20] Kehr, F., Kowatsch, T., Wentzel, D., and Fleisch, E. Thinking Styles and Privacy Decisions: Need for Cognition, Faith into Intuition, and the Privacy Calculus. 12th International Conference on Wirtschaftsinformatik, (2015), 1-14.

[21] Kehr, F., Kowatsch, T., Wentzel, D., and Fleisch, E. Blissfully ignorant: the effects of general privacy concerns, general institutional trust, and affect in the privacy calculus. Information Systems Journal 25, 6 (2015), 607-635.

[22] Kehr, F., Wentzel, D., Kowatsch, T., and Fleisch, E. Rethinking Privacy Decisions : Pre-Existing At- Titudes, Pre-Existing Emotional States, and a Situational Privacy Calculus. European Conference on Information Systems, (2015), 1-15.

[23] Kehr, F., Wentzel, D., and Mayer, P. Rethinking the Privacy Calculus: On the Role of Dispositional Factors and Affect. Proceedings of the International Conference on Information Systems, 1 (2013), 1-10.

[24] Keith, M.J., Thompson, S.C., Hale, J., Lowry, P.B., and Greer, C. Information Disclosure on Mobile Devices: Re-examining Privacy Calculus with Actual User Behavior. International Journal of HumanComputer Studies 71, 12 (2013), 1163-1173.

[25] Kuo, K. and Talley, P.C. An Empirical Investigation of the Privacy Concerns of Social Network Site Users in Taiwan. Computing and
Information Technology 5, 2 (2014), 1-19.

[26] Li, H., Sarathy, R., and Xu, H. The Role of Affect and Cognition on Online Consumers' Decision to Disclose Personal Information to Unfamiliar Online Vendors. Decision Support Systems 51, 3 (2011), 434445.

[27] Malhotra, N.K., Kim, S.S., and Agarwal, J. Internet Users' Information Privacy Concerns (IUIPC): The Construct, the Scale, and a Causal Model. Information Systems Research 15, 4 (2004), 336-355.

[28] Milne, G.R., Culnan, M.J., and Greene, H. A Longitudinal Assessment of Online Privacy Notice Readability. Journal of Public Policy \& Marketing 25, 2 (2006), 238-249.

[29] Milne, G.R. and Rohm, A.J. Consumer privacy and name removal across direct marketing channels: Exploring opt-in and opt-out alternatives. Journal of Public Policy \& Marketing 19, 2 (2000), 238-249.

[30] Norberg, P. a, Horne, D.R., and Horne, D.A. The Privacy Paradox: Personal Information Disclosure Intentions versus Behaviors. The Journal of Consumer Affairs 41, I (2007), 100-127.

[31] Park, Y.J. Digital Literacy and Privacy Behavior Online. Communication Research 40, 2 (2013), 215-236.

[32] Park, Y.J. and Mo Jang, S. Understanding privacy knowledge and skill in mobile communication. Computers in Human Behavior 38, SEPTEMBER 2014 (2014), 296-303.

[33] Rader, E. Awareness of Behavioral Tracking and Information Privacy Concern in Facebook and Google. Symposium on Usable Privacy and Security (SOUPS), (2014), 51-67.

[34] Sim, I., Linglal, D., and Khansa, L. Information Privacy Situation Awareness: Construct and Validation. Journal of Computer Information Systems 53, 1 (2012), 57-64.

[35] Smith, H.J., Dinev, T., and Xu, H. Theory and Review Information Privacy Research: an Interdisciplinary Review. MIS Quarterly 35, 4 (2011), 989-1015.

[36] Smith, H.J., Milberg, S.J., and Burke, S.J. Information Privacy: Measuring Individuals' Concerns About Organizational Practices. MIS Quarterly 20, 2 (1996), 167-196.

[37] Stewart, K.A. and Segars, A.H. An Empirical Examination of the Concern for Information Privacy Instrument. Information Systems Research 13, 1 (2002), 36-49.

[38] Sun, Y., Wang, N., Shen, X.-L., and Zhang, J.X. Location information disclosure in location-based social network services: Privacy calculus, benefit structure, and gender differences. Computers in Human Behavior 52, November (2015), 278-292.

[39] Trepte, S., Teutsch, D., Masur, P., et al. Do 
People Know About Privacy and Data Protection Strategies? Towards the "Online Privacy Literacy Scale" (OPLIS). 2015.

[40] Tschersich, M. and Botha, R.A. Exploring the impact of restrictive Default Privacy Settings on the Privacy Calculus on Social Network Sites. Proceedings of the European Conference on Information Systems, (2014), 1-14.

[41] Turow, J. Americans and Online Privacy - The System is Broken. Annenberg Public Policy Center Report, (2003), 1-36.

[42] Turow, J., Feldman, L., and Meltzer, K. Open to Exploitation: America's Shoppers Online and Offline. A Report from the Annenberg Public Policy Center of the University of Pennsylvania, (2005), 10.

[43] Webster, J. and Watson, R.T. Analyzing the Past to Prepare for the Future: Writing a Literature Review. MIS Quarterly 26, 2 (2002), xiii-xxiii.

[44] Wickens, C.D. Situation Awareness: Review of Mica Endsley's 1995 Articles on Situation Awareness Theory and Measurement. Human factors 50, 3 (2008), 397-403.

[45] Wilson, D. and Valacich, J. Unpacking the Privacy Paradox: Irrational Decision-Making within the Privacy Calculus. Proceedings of the International Conference on Information Systems, (2012), 1-11.

[46] Xu, H., Dinev, T., Smith, J., and Hart, P. Information Privacy Concerns: Linking Individual Perceptions with Institutional Privacy Assurances. Journal of the Association for Information Systems 12, 12 (2011), 798-824.

[47] Yun, H., Lee, G., and Kim, D.J. A MetaAnalytic Review of Empirical Research on Online Information Privacy Concerns: Antecedents, Outcomes, and Moderators. Proceedings of the International Conference on Information Systems, (2014), 1-13.

[48] Encyclopedia. 2009. http://www.encyclopedia.com/topic/aware.aspx.

[49] The Data Brokers: Selling your personal information. CBS News, 2014. http://www.cbsnews.com/news/the-data-brokersselling-your-personal-information/.

[50] Privacy in the Digital Age | Pew Research Center. 2015. http://www.pewinternet.org/2015/06/03/privacy-in-thedigital-age/.

Table 1. Definitions of awareness

\begin{tabular}{|c|c|}
\hline Borena \& Balanger, 2015 & $\begin{array}{l}\text { "Privacy awareness indicates users' knowledge of privacy issues, privacy violations, } \\
\text { and solutions" (Jiang, 2011) (we could not locate this study). p.8 }\end{array}$ \\
\hline Burkell et al., 2015 & $\begin{array}{l}\text { "Policy awareness and compliance: exposure to pertinent local, provincial, federal, } \\
\text { and international information policy and regulation, with a focus on needs specific } \\
\text { to Canadian organizations." p.iv }\end{array}$ \\
\hline Brecht et al., 2012 & $\begin{array}{l}\text { "Privacy Awareness' measures the awareness of Internet users regarding a general } \\
\text { existence and possibility of Internet privacy issues, without focusing on technical } \\
\text { details or on a particular user." p.3 }\end{array}$ \\
\hline Dinev \& Hart, 2006b & $\begin{array}{l}\text { "Social awareness is defined as citizens' behavior with respect to following and } \\
\text { being interested in and knowledgeable about community and government policies } \\
\text { and initiatives, including those related to technology and the Internet." p.11 }\end{array}$ \\
\hline Ermakova et al., 2014 & $\begin{array}{l}\text { "Privacy awareness refers to the degree to which an individual is informed about } \\
\text { privacy issues." p.4 }\end{array}$ \\
\hline Kuo \& Talley, 2014 & $\begin{array}{l}\text { "That is, users should be informed that SNSs will collect their personal information, } \\
\text { and then the collected information may be shared with third parties. This belief } \\
\text { basically reflects the construct of awareness which will be integrated into our } \\
\text { model." p.4 }\end{array}$ \\
\hline Li et. al., 2011 & $\begin{array}{l}\text { "Awareness of privacy statement APS - An individual's awareness of the content in } \\
\text { the privacy statement of a Web site." p. } 4\end{array}$ \\
\hline Malhotra et al., 2004 & $\begin{array}{l}\text { "Awareness factor indicates understanding about established conditions and actual } \\
\text { practices. p.338" }\end{array}$ \\
\hline Xu et al., 2008 & $\begin{array}{l}\text { "Privacy awareness reflects the extent to which an individual is informed about } \\
\text { privacy practices and policies, about how disclosed information is used, and is } \\
\text { cognizant about their impact over the individual's ability to preserve her private } \\
\text { space (Donaldson 1989; Donaldson and Dunfee 1994; Dunfee et al. 1999; Phelps et } \\
\text { al. 2000)." p.6 }\end{array}$ \\
\hline Yun et al., 2014 & $\begin{array}{l}\text { "The extent to which an individual is informed about the available technology, } \\
\text { service, or practice (e.g., privacy policy)" p. } 4\end{array}$ \\
\hline
\end{tabular}


Table 2. Measurement of awareness \& use of aware/awareness

\begin{tabular}{|c|c|c|c|c|c|c|c|c|c|c|c|c|c|c|c|c|c|c|c|c|c|c|c|}
\hline & \multicolumn{14}{|c|}{ Measured } & \multicolumn{9}{|c|}{ Used } \\
\hline Author & $\sum$ & $\frac{\overleftrightarrow{\Xi}}{\stackrel{\Xi}{\Xi}}$ & 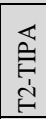 & 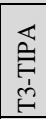 & 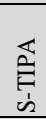 & 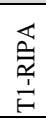 & 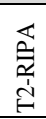 & 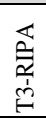 & 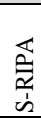 & 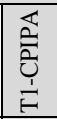 & 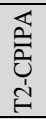 & 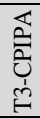 & 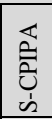 & 方 & 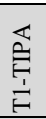 & 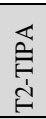 & 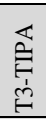 & $\frac{\overleftrightarrow{\mid}}{\stackrel{a}{\mid}}$ & 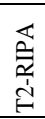 & 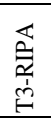 & 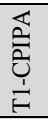 & 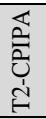 & 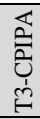 \\
\hline (Acquisti \& Gross, 2006) & & & & & & & & & & & & & & $\mathrm{X}$ & & $\mathrm{X}$ & & & & & $\mathrm{X}$ & $\mathrm{X}$ & $\mathrm{X}$ \\
\hline (Acquisti \& Grossklags, 2005) & & & & & & & & & & & & & & & & & & $\mathrm{X}$ & & & $\mathrm{x}$ & & \\
\hline (Acquisti, 2004) & & & & & & & & & & & & & & $\mathrm{X}$ & & & & & & & $\mathrm{X}$ & & $\mathrm{X}$ \\
\hline (Bansal et al., 2010) & & & & & & & & & & & & & & & $\mathrm{X}$ & & & & & & $\mathrm{X}$ & & $\mathrm{X}$ \\
\hline (Borena \& Tech, 2015) & & & & & & & & & & & $\mathrm{X}$ & $\mathrm{X}$ & $\mathrm{X}$ & & & & & & & & $\mathrm{X}$ & & \\
\hline (Boritz \& No, 2011) & & & & & & & & & & & & & & & & & & & & & $\mathrm{X}$ & & \\
\hline (Brecht et al., 2012) & & & & & & & & & & & & & & $\mathrm{X}$ & $\mathrm{X}$ & $\mathrm{X}$ & & & & & $\mathrm{X}$ & & \\
\hline (Burkell et al., 2015) & & & & & & & & & & & & & & & $\mathrm{X}$ & & $\mathrm{X}$ & $\mathrm{X}$ & & & $\mathrm{X}$ & & \\
\hline (Clemons \& Wilson, 2015) & & & & & & & & & & $\mathrm{x}$ & & & & & & & & & & & $\mathrm{X}$ & $\mathrm{X}$ & $\mathrm{X}$ \\
\hline (Conger et al., 2013) & & & & & & & & & & & & & & & $\mathrm{x}$ & & & & & & $\mathrm{x}$ & & $\mathrm{X}$ \\
\hline (Culnan, 1993) & $\mathrm{X}$ & & & & & & & & & $\mathrm{x}$ & $\mathrm{X}$ & & & & & & & & & & $\mathrm{X}$ & & \\
\hline (Culnan, 1995) & $\mathrm{X}$ & & & & & & & & & $\mathrm{x}$ & & & & & & & & & & & $\mathrm{X}$ & $\mathrm{x}$ & $\mathrm{x}$ \\
\hline (Debatin et al., 2009) & & & & & & & & & & & & & & & & & & & & & $\mathrm{x}$ & & $\mathrm{X}$ \\
\hline (Dinev \& Hart, 2006a) & & & & & & & & & & & & & & & & & & & & & $\mathrm{X}$ & & \\
\hline (Dinev \& Hart, 2006b) & $\mathrm{X}$ & $\mathrm{x}$ & & & & & & & & & & & $\mathrm{X}^{*}$ & & & & & $\mathrm{X}$ & & & $\mathrm{X}$ & & $\mathrm{X}$ \\
\hline (Dommeyer \& Gross, 2003) & $\mathrm{X}$ & & & & & & & & & & $\mathrm{X}$ & & $\mathrm{X}$ & & & & & & & & $\mathrm{X}$ & $\mathrm{X}$ & \\
\hline (Ermakova et al., 2014) & $\mathrm{X}$ & $\mathrm{X}$ & $\mathrm{X}$ & & & & & & & $\mathrm{X} * *$ & & & $\mathrm{X}$ & & & & & & & & $\mathrm{X}$ & & \\
\hline (Hong \& Thong, 2013) & & & & & & & & & & $\mathrm{x}$ & $\mathrm{X}$ & & $X^{*}$ & & & & & & & & $\mathrm{x}$ & $\mathrm{x}$ & $\mathrm{X}$ \\
\hline (Hui et al., 2007) & & & & & & & & & & & & & & & & & & & & & $\mathrm{x}$ & & \\
\hline (Jensen \& Potts, 2005) & & & & & & & & & & & & & & & & & & & & & $\mathrm{X}$ & & \\
\hline (Kauffman et al., 2011) & & & & & & & & & & & & & & & $\mathrm{X}$ & & & & & & $\mathrm{X}$ & $\mathrm{X}$ & \\
\hline (Keith et al., 2013) & & & & & & & & & & & & & & & & & & & & & & & $\mathrm{X}$ \\
\hline (Kordzadeh \& Warren, 2014) & & & & & & & & & & & & & & & & & & & & & & & $\mathrm{x}$ \\
\hline (Kuo \& Talley, 2014) & & & & & & & & & & & $\mathrm{X}$ & $\mathrm{X}$ & $\mathrm{X}^{*}$ & & & & & & & & $\mathrm{X}$ & $\mathrm{X}$ & $\mathrm{X}$ \\
\hline (Lee \& Kim, n.d.) & & & & & & & & & & & $\mathrm{X}$ & $\mathrm{X}$ & $\mathrm{x}$ & & & & & & & & $\mathrm{x}$ & & \\
\hline (Li \& Carolina, 2011) & & & & & & & & & & & & & $\mathrm{x}$ & & & & & & & & & & \\
\hline (Malhotra et al., 2004) & $\mathrm{X}$ & & & & & & & & & & $\mathrm{X}$ & $\mathrm{X}$ & $X^{*}$ & & & & & & & & $\mathrm{x}$ & $\mathrm{x}$ & $\mathrm{x}$ \\
\hline (Milne \& Rohm, 2000) & $\mathrm{X}$ & & & & & & & & & & $\mathrm{X}$ & & & & & & & & & & $\mathrm{X}$ & $\mathrm{X}$ & \\
\hline (Morrison, 2013) & $\mathrm{X}$ & & & & & $\mathrm{X}$ & & & & $\mathrm{x}$ & & & $\mathrm{X}^{*}$ & & & & & $\mathrm{X}$ & & & $\mathrm{x}$ & $\mathrm{X}$ & \\
\hline (Norberg \& Horne, 2007) & & & & & & & & & & & & & & & & & & & & & & & $\mathrm{X}$ \\
\hline (Nowak \& Phelps, 1992) & & & & & & & & & & $\mathrm{x}$ & & & & & & & & & & & $\mathrm{X}$ & & \\
\hline (Park \& Jang, 2014) & & & & $\mathrm{X}$ & & $\mathrm{X}$ & $\mathrm{X}$ & & & $\mathrm{x}$ & $\mathrm{X}$ & & & & & & & & & & $\mathrm{X}$ & & \\
\hline (Park et al., 2012) & & & & & & $\mathrm{X}$ & $\mathrm{X}$ & $\mathrm{X}$ & & & & & & & & & & $\mathrm{X}$ & & & $\mathrm{x}$ & & $\mathrm{x}$ \\
\hline (Park, 2013) & & $\mathrm{X}$ & & & & $\mathrm{X}$ & $\mathrm{X}$ & $\mathrm{X}$ & & $\mathrm{x}$ & $\mathrm{X}$ & $\mathrm{X}$ & & & $\mathrm{x}$ & & & & & & $\mathrm{X}$ & $\mathrm{X}$ & $\mathrm{x}$ \\
\hline (Perreault, 2015) & & & & & & & & & & & $\mathrm{X}$ & $\mathrm{X}$ & $X^{*}$ & & & & & & & & & $\mathrm{X}$ & $\mathrm{x}$ \\
\hline (Rader, 2014) & $\mathrm{X}$ & & & & & & & & & $\mathrm{x}$ & $\mathrm{x}$ & & & & & & & & & & $\mathrm{x}$ & $\mathrm{X}$ & $\mathrm{x}$ \\
\hline (Stewart \& Segars, 2002) & & & & & & & & & & & & & & & & & & & & & $\mathrm{X}$ & & \\
\hline (Trepte et al., 2015) & $\mathrm{x}$ & $\mathrm{X}$ & & & & $\mathrm{X}$ & & & & $\mathrm{x}$ & $\mathrm{X}$ & $\mathrm{X}$ & & & $\mathrm{X}$ & $\mathrm{X}$ & & & & & $\mathrm{x}$ & $\mathrm{X}$ & $\mathrm{x}$ \\
\hline (Tsai et al., 2011) & & & & & & & & & & & & & & & & & & & & & $\mathrm{X}$ & $\mathrm{X}$ & $\mathrm{X}$ \\
\hline (Tschersich \& Botha, 2014) & & & & & & & & & & & & & & $\mathrm{X}$ & & & & & & & $\mathrm{X}$ & & \\
\hline (Turow et al., 2005) & $\mathrm{X}$ & & & & & $\mathrm{X}$ & $\mathrm{X}$ & & & $\mathrm{x}$ & $\mathrm{X}$ & & & & & & & $\mathrm{X}$ & & & $\mathrm{x}$ & & \\
\hline (Turow, 2003) & & $\mathrm{X}$ & $\mathrm{X}$ & & & & & & $\mathrm{X}$ & & $\mathrm{X}$ & $\mathrm{X}$ & & & $\mathrm{X}$ & $\mathrm{x}$ & $\mathrm{x}$ & & & & $\mathrm{x}$ & $\mathrm{X}$ & $\mathrm{X}$ \\
\hline (Wilson \& Valacich, 2012) & & & & & & & & & & & & & & $\mathrm{X}$ & & & & & & & & & \\
\hline (Xu et al., 2008) & $\mathrm{X}$ & & & & & & & & & $\mathrm{x}$ & & & $\mathrm{x}$ & & & & & & & & $\mathrm{x}$ & & $\mathrm{X}$ \\
\hline (Xu et al., 2011) & & & & & & & & & & $\mathrm{x}$ & & & $\mathrm{X}$ & & & & & & & & $\mathrm{X}$ & $\mathrm{x}$ & \\
\hline
\end{tabular}

$\mathrm{X}^{*}=$ subjective questions measuring something other than awareness, $\mathrm{X}^{* *}=$ study including both subjective and objective awareness questions, NP $=$ Not Provided, $\mathrm{DM}=$ Developed Measure, QNP $=$ Questions Not Provided ${ }^{* * *}$ Detailed references are available by request from the first author*** 